\title{
Design Guideline for Flexible Industrial Buildings Integrating Industry 4.0 Parameters
}

\author{
Julia Reisinger * (D), Patrick Hollinsky and Iva Kovacic \\ Department of Integrated Planning and Industrial Building, Technical University of Vienna-TU Wien, \\ 1040 Wien, Austria; patrick.hollinsky@gmail.com (P.H.); iva.kovacic@tuwien.ac.at (I.K.) \\ * Correspondence: julia.reisinger@tuwien.ac.at
}

Citation: Reisinger, J.; Hollinsky, P.; Kovacic, I. Design Guideline for Flexible Industrial Buildings Integrating Industry 4.0 Parameters. Sustainability 2021, 13, 10627. https:/ / doi.org/10.3390/su131910627

Academic Editors: Mladen Vukomanovic and Michał Juszczyk

Received: 29 July 2021

Accepted: 15 September 2021

Published: 24 September 2021

Publisher's Note: MDPI stays neutral with regard to jurisdictional claims in published maps and institutional affiliations.

Copyright: (c) 2021 by the authors. Licensee MDPI, Basel, Switzerland. This article is an open access article distributed under the terms and conditions of the Creative Commons Attribution (CC BY) license (https:// creativecommons.org/licenses/by/ $4.0 /)$.

\begin{abstract}
The emergence of Industry 4.0 can contribute to sustainable development, but most concepts have not yet received much attention in industrial building design. Industry 4.0 aims to realize production in batch size of one and product individualization on demand. Constant reconfiguration and expansion of production systems demand highly flexible building structures to prolong service life and reduce economic and environmental impacts. However, most research and tools focus on either production system or building optimization. There is a lack of holistic approaches that combine these two aspects. This paper presents a systematic design guideline for flexible industrial buildings towards the requirements of Industry 4.0, integrating building and production planning. The methodology employs literature research and a multiple case study based on expert interviews. The design guideline is presented in the form of a categorized parameter catalogue that classifies the results, on the one hand, into the levels of $(\mathrm{O})$ objectives, $(\mathrm{T})$ technical parameters and $(\mathrm{P})$ planning process, and on the other hand, into (S) success factors, (I) suggestions for improvement and (D) deficits. The findings identify flexibility, structural design parameters and an integrated computational design approach at early design stage as potential success factors for integrated industrial building design (IIBD). The results set the basis to develop a multi-objective optimization and decision-making support tool for IIBD in future research.
\end{abstract}

Keywords: integrated industrial building design; Industry 4.0; sustainable building design; flexible production facilities; integrated design; design guidance

\section{Introduction}

Industry 4.0 has received much attention in recent years and describes the trend towards increased digitization and automation of the manufacturing environment [1]. The concept mainly includes enabling technologies such as cyber-physical systems (CPS), Internet of Things (IoT) and cloud computing [2], resulting in a paradigm shift in industrial production [3]. While originally applied to manufacturing systems, the digital transformation of the fourth industrial revolution is also changing the construction sector [4]. However, usually, this concept mainly focuses on the dimensions of production and economic profits. This limited perspective creates multiple problems for other dimensions and often neglects sustainability aspects [5].

The construction industry is crucial for sustainable development as buildings account for $30 \%$ to $40 \%$ of the primary energy use worldwide [6] and consume up to $40 \%$ of all raw materials [7]. In particular, industrial buildings, here defined as facilities in which products are manufactured, play a key role in sustainable development as they produce and consume a significant amount of material, energy and waste in the construction and operation phases [8]. The emergence of Industry 4.0 can contribute to achieving the Sustainable Development Goals (SDGs) [9] by evolving digital sustainable operations [10], yet most of the concepts have not gained much attention in the construction industry [1]. The essence of Industry 4.0 is inter- and transdisciplinary integration of existing and new 
technologies [2]. Due to upcoming sustainability requirements, a more integrated practice in building design and a focus on early design stages is needed. This holistic approach enables and promotes the collaboration of multiple disciplines and offers real-time decisionmaking supports [11]. A high fragmentation of building design processes hinders the communication and management of complex design decisions. It is also challenging for scattered stakeholders to assess the impact of decisions on the project performance [12]. Moreover, interfaces and data exchange between the domain-disciplines in factory design have been little researched [13], making the integration of production system planning and building design challenging [14]. Consequently, in order to enhance sustainability, the focus should be on integrated industrial building design (IIBD), incorporating building and production planning methods already at the early design stage.

Prior research has shown that flexibility can improve the sustainability of manufacturing processes [15] and building designs [16,17]. Industry 4.0 aims to realize production in batch size of one and individualization on demand within short development periods [3]. Constant reconfiguration and expansion of production systems demand highly flexible building systems to prolong the factories service life, thereby decreasing the economic and environmental impact [18]. Yet there is a lack of formal design guidance supporting flexibility within architectural and engineering systems used for production facilities [19]. Usually, the building is planned around the product and process requirements not incorporating the capability to respond quickly enough to changes [20]. Thus, to improve the design outcome and reduce the environmental impact of industrial buildings, the building systems (envelope, load-bearing structure, building service equipment) should be designed towards increased flexibility to enable reconfiguration of manufacturing systems.

The load-bearing structure, as the most rigid element with the longest service life in a building [21] is a key determinant of the adaptability and transformability of manufacturing systems. Flexible load-bearing structures, which can be implemented by means of wide-span ceiling or girder systems, sufficiently high stories and different load carrying capacities, can prolong the building's service life [22]. Maximizing the flexibility of building structures can minimize costs and time required for rescheduling and the identification of interdependencies to other discipline-specific systems is challenging [23]. Currently available structural analysis tools are not sufficient for the early design stage as they tend to focus on precision rather than flexibility. They also lack interoperability with other design tools [24]. Furthermore, most structural analysis methods provide feedback only to the structural engineer and do not support an integrated performance improvement [25]. Digital industrial building models that do not properly address the interaction between production and building design disciplines may later lead to inflexible solutions. The same lack of flexibility may result if structural considerations are subservient to architectural and production goals. Thus, a precondition for the realization of flexible industrial buildings for Industry 4.0 is the optimization of the load-bearing structure early in the design process and the integration of a high number of interrelated discipline-specific design parameters.

An IIBD approach requires the utilization of powerful digital tools, which allow holistic simulation, prediction and optimization to support close collaboration of all stakeholders. The digital transformation of the construction industry can be seen as a new opportunity to overcome the lack in productivity by pushing the collaboration in an interdisciplinary data-driven environment [26]. However, the models, data and processes of the disciplines involved in planning and operating of factories lack interoperability and are kept in discipline-specific silo thinking [27]. Regarding optimization and decision-support tools in factory planning, prior research has mostly been focusing on optimization on product- or manufacturing process level $[28,29]$, energy efficiency in production $[30,31]$ or sustainable manufacturing $[32,33]$ and paid less attention to the integration of building structure or -services information [8]. Several authors proposed models concentrating on the industrial building, evaluating the environmental performance of building elements through lifecycle assessment [34-36] or optimizing the buildings' energy performance [37,38]. Holistic digital models that optimize industrial building structures towards maximum flexibility, 
thus sustainability, receive little attention and fail to fully incorporate both production and building design.

Hence, to enable the realization of sustainable industrial buildings, load-bearing structures of maximum flexibility are required for rapid reconfigurability and adaptability of production systems. A prerequisite for IIBD is the integrated collaboration of all stakeholders from the early design stage and the development of powerful digital tools with efficient user interfaces that incorporate building and production planning knowledge. In this context, this paper addresses the lack of formal guidelines that support the design of flexible industrial buildings for the requirements of Industry 4.0 and integrate the parameters of production and building design. The main research questions addressed in this paper are: what are the critical parameters for a holistic design approach that combines building and production planning and how to generate methods, models and processes for flexible and sustainable production facilities? To answer the research questions, the following hypotheses are investigated in this paper:

Hypothesis 1 (H1). The primary objective for the realization of sustainable industrial buildings is to maximize the flexibility in order to accommodate the fast-moving processes of Industry 4.0.

Hypothesis 2 (H2). The optimization of the load-bearing structure at the early design stage is crucial for enhancing the flexibility of industrial buildings.

Hypothesis 3 (H3). The optimization towards maximum flexibility is characterized by a high degree of complexity and interdependencies of interdisciplinary parameters and therefore requires an integrated planning approach supported by powerful computational tools.

This paper presents ongoing research conducted within the funded research project BIMFlexi, which aims to develop a digital platform for design and optimization of flexible industrial buildings towards the needs of Industry 4.0 by integrating production and building planning. The goal of the presented research is to develop a systematic design guideline for sustainable industrial building design for Industry 4.0 that integrates building and production planning knowledge in form of a categorized parameter catalogue. The research employs the methods of literature research and expert interviews within a multiple case study to identify $(\mathrm{O})$ objectives, $(\mathrm{T})$ technical parameters and $(\mathrm{P})$ demands on the planning process in IIBD. By analyzing the core content of the expert statements gathered from the interviews, the parameters are further classified into (S) success factors, (I) suggestions for improvement and (D) deficits. The results of this paper serve as basis for the development of a holistic simulation, optimization and decision-making support tool for flexible IIBD, which will be addressed in the next steps of our research.

This paper is structured as follows: in the next section, the state of the art and research on Industry 4.0, flexibility and design parameters, data and model integration and decision-making support in IIBD is examined through literature review. Second, the methodology is described, where a multiple case study of five real industrial building projects with 15 conducted expert interviews is presented, followed by the analysis of the questionnaire results. Based on the analysis results, the developed design guideline in form of a categorized parameter catalogue is presented. In the concluding section, future steps and challenges are discussed.

\section{Literature Review}

The main purpose of this research is to create a design guideline for the realization of flexible industrial buildings considering Industry 4.0 needs. The study aims to increase the sustainability of production facilities through integration of building design and production planning. 


\subsection{Industry 4.0 and Sustainable Industrial Building Design}

Sustainability at an economic, ecological and social level is an increasingly important goal in factory planning processes [39]. Industry 4.0 technologies can enable the achievement of sustainability by acting as a novel driver of traditional supply chains through digitization with the aim of resource efficiency and circularity. The development of new concepts for sustainable Industry 4.0 can lead to a greater efficiency of functions or actions by using IT-based technologies and tools for industry-specific data exchange and storage, to manage big data, to increase transparency and to improve resource efficiency [10]. Nevertheless, as Industry 4.0 concepts deploy scenarios of digitization, integration and automation, they require more materials, energy and disposal as the infrastructure needs new highly demanding machines, software, and hardware [5]. Apart from the energy and material used by manufacturing processes, industrial buildings consume considerable amounts of energy, materials and waste for construction and operation. Oesterreich and Teuteberg [1] point to benefits the construction industry could obtain through Industry 4.0 , but the resource and energy optimization of industrial buildings have been regarded as secondary issues compared to the management of the production processes and workforce $[34,38]$. Industrial building and production systems are generally heavy, fixed, and normally irreversible once construction has been completed [40]. The service life of a building is highly dependent on the durability of the physical structure, whereas the longest lasting building component is the load-bearing structure. The load-bearing structure has a service life of approximately 30 to 300 years; in comparison to the exterior building enclosure which changes every 20 years and the building service equipment which has a lifetime of 7 to 15 years [21]. The economic life cycle of industrial buildings is characterized by very short life cycles ranging from 15 to 30 years, compared to classical buildings that range from 50 to 80 years. The prolongation of industrial buildings service life could increase economic and environmental performance but demands that the building structure accommodates flexible and expandable production layouts [18]. Geraedts [41] establishes a direct link between the flexibility of a building and its sustainability. By extending the buildings service life, the energy and emissions required to construct and operate the building can be better distributed over the years of use. Thus, the focus in flexible industrial building design needs to be on a coherent planning and respecting objectives and parameters of both the rigid building and flexible production systems.

\subsection{Flexibililty and Design Parameters in IIBD}

It is widely acknowledged in the research and industry communities that flexible, adaptable and expandable buildings increase sustainability. Incorporating flexibility early in the design process can reduce lifetime investments in production facilities which are subject to change [42]. The flexibility of a building can be defined as its capacity to adapt to changes in use [43], while a flexible production enables the response to customer orders quickly, provides a broad product range, or introduces new products to the range effortlessly [44]. Various research defined concepts and metrics for flexibility in residential building design [17,45-47] or the adaptive re-use of office and industrial buildings [48]. Slaughter [23] presents three general types of expected building changes: changes in the function of the space, changes in the load carried by the systems and changes in the flow of people or environmental forces. Further factors influencing the buildings flexibility are the material standards, production, planning for future changes and service life, installations, financial aspects and the aspects of awareness on building flexibility [49]. Cavalliere, et al. [17] define metrics of housing flexibility such as structural modularity, geometrical regularity of plan, location of technical service, removable building elements, percentage/orientation of windows and internal mobile partitions. Geraedts [41] identifies flexibility key performance indicators and divides them in the layers of site, structure, skin, facilities and space. The indicators for structural flexibility include the surplus of the building space and floor, the surplus of free floor height, the surplus of the loadbearing capacity and the positioning of columns or facility zones, while the building 
service equipment respect the surplus capacity of facilities, distribution facilities, location sources facilities along with others. Madson, et al. [19] highlighted the lack of formal design guidance, supporting flexibility within architectural and engineering systems of production facilities and describe design features for flexible manufacturing facilities such as additional floor space, fixed utility routing, additional floor-to-ceiling height, preinvestment in foundation, large column bays, modular production area and others. On the manufacturing side, Browne et al. [50] and Sethi and Sethi [51] defined the eleven most common production flexibility dimensions as: machine flexibility, operation flexibility, routing flexibility, volume flexibility, expansion flexibility, process flexibility, product flexibility, production flexibility, material handling flexibility, programme flexibility and market flexibility but neglected the factor building. Wiendahl et al. [52] introduces the term changeable manufacturing as characteristic to accomplish foresighted adjustments of the production facility structures and processes on all levels, including the factor building and describe the five transformation enablers as universality, scalability, modularity, mobility and compatibility. Other research considered the flexible design of a specific facility type such as food processing facilities [53] and pharmaceutical facilities [54]. However, the term flexibility in production is not uniform and faces three issues: (1) measuring flexibility is not easy; (2) the produced products of a plant do not always reflect its flexibility and (3) it is often unclear which general features of a plant must be changed in order to make its operations flexible [44]. A rising number of research has investigated concepts and criteria of flexibility in both building and production planning. However, flexibility in production facilities is not a one-size-fits-all approach; rather it can be cultivated at varying levels by a series of design choices [19]. The stakeholder needs decision rules to guide the use of flexibility as the choice of design decisions affect the lifecycle performance of the system, benefitting from guidance and thorough evaluation [55]. Therefore, the definition of joint design parameters for IIBD is the focus of this paper in order to provide design guidance towards flexible industrial buildings by integrating Industry 4.0 needs to support in optimization and decision-making at early project stages.

In addition to flexibility, previous research on industrial building design and construction has focused on sustainability performance, typical design criteria, processes and models. Shen, et al. [56] described the major factors affecting sustainability performance across a construction projects lifecycle and suggest considering life-cycle costs, project layout, material choice, knowledge of designers, effective communication among stakeholders and modular/standardized design to reduce waste. Shen, et al. [57] defined key assessment factors to assess the sustainability performance of infrastructure projects as stating life-cycle costs, ecological effects, effect on land, air and water, waste generation and energy savings. Rodrigues, et al. [35] stated that building materials especially the ones from load-bearing structure and enclosure systems are the main responsible for the total embodied energy and carbon in industrial buildings. As the element with the longest service life, the structural system has a vast impact on the life-cycle performance of production systems [58,59]. Nadoushani and Akbarnezhad [60] described the lateral load resisting system, material of the structure and the height of the structure as important parameter in structural hall design. San-José Lombera and Garrucho Aprea [58] presented an integrated value model for sustainable assessment of industrial buildings, defining sustainability criteria under the study cope of functionality, economy, environment, social, safety and aesthetics. Lee, et al. [61] developed a factorial design space exploration approach to support in multi-criteria design decision-making (MCDM), investigating the energy performance, environmental impact and cost effectiveness across the life-cycle, identifying the design parameter for interest are insulation values, construction types, skylight coverage and transpired solar collector coverage. Vardopoulos [62] investigated critical sustainable development factors of industrial buildings for adaptive reuse such as energy efficiency, extending the life cycle of buildings and materials, reduce greenhouse gases, reduce resource consumption and prevent urban sprawl. The above-mentioned research is remarkable but neglects the impact of changing production systems. Wiendahl, et al. [63] present 
parameters and dependencies of production and building design in factories, describing primary building design criteria as demountable façade systems, enclosure system type, primary and secondary load-bearing structure type, axis grid, dimensioning and position of foundations and sprinkler systems for fire safety. A variety of research is investigating and identifying parameters for flexible industrial building design and production planning. However, a holistic summary of all relevant parameters in IIBD is lacking.

\subsection{Data and Model Integration}

Integrated planning in industrial building design requires a high degree of networking, coupling and coordination of processes and discipline-specific models for all involved stakeholders, leading to increased complexity. Woodhead, et al. [64] see data integration as the key factor for value creation and a need to overcome the tendency to use point solutions in construction industry. However, the goal of seamless global software interoperability in construction industry is far from being achieved [65]. The application of Building Information Modelling (BIM) bears the potential to support integrated production and building planning [1]. BIM is seen as catalyst to bring more innovation and integration in the building sector, which is still caught in silo-thinking and sequential processes. BIM can be defined as a planning tool, but more over as a planning method and modelling process. BIM addresses both geometrical- and non-geometrical data (i.e., costs, technical properties) and aims to support data exchange within an interdisciplinary planning process [66]. BIM offers a common digital knowledge platform integrating the activities of all stakeholders along the construction value chain through improved communication and coordination between stakeholders [67,68]. BIM and computer-aided simulations are already used in isolated cases, but the applications are still in classical domain-specific thinking and silo attitude of the data of the different planning disciplines, resulting in information and data losses [69]. Moreover, the integration of production planning and building design is a major challenge for BIM processes and tools [14], as there has been little research on BIM applications and workflows, interfaces and data exchange with other related departments in manufacturing companies [13]. Currently, building and production planning processes run sequentially and neglect discipline-specific interactions [70]. Major obstacles in integrating building and production planning models and processes are due to missing maturity level specifications and missing data management standards [27]. Some researchers focus on the integration of factory planning processes such as the managing of interdependencies and information of different tasks [70-73], the overall project management using component-based synthesis [74] or the integration of production planning into BIM-based building models for the operation phase $[75,76]$. The literature review shows that there are many research efforts on digital integration of industrial building design and production planning methods. Despite the fact that the integration of discipline-specific data and models could support decision-making and lead to improvement performance, there is currently a lack of holistic integration in IIBD.

\subsection{Decision-Making Support in IIBD}

Decisions made at early design stage, such as during the program and schematic design stages, have a major impact on the building performance and one need to develop design alternatives, which must be evaluated, refined, evolved and finally optimized early on [77]. Furthermore, decisions on building flexibility [78] and manufacturing flexibility [29] are more impactful when made at early design stage. An integrated design approach where all systems and components work together can lead to well-designed and cost-effective buildings, improving the overall functionality and environmental performance. Decision-making in design entails the process of generating, evaluating, and determining design alternatives to satisfy given requirements or criteria [79]. In IIBD, stakeholders are faced with the choice of multiple conflicting parameters and a vast number of complex design decisions, highlighting the need of guided decision support. The factory planning process needs quantitative evaluation of designs and systematic decision 
support [80]. A holistic digital factory model builds upon three fundamental components: a target setting/calculation model, a heterogeneous data integration and sufficient decision support [71]. Numerous research studies have been conducted regarding optimization and decision-support tools for manufacturing systems. Büscher et al. [28] presented the concept of virtual production intelligence for an integrative information system, enabling planners to integrate, to aggregate and to analyze data gathered during planning projects. Francalanza et al. [29] developed a knowledge-based decision-making approach for designing changeable manufacturing systems. Kluczek [33] presented an MCDM approach to assess the sustainability of manufacturing processes and Mousavi et al. [30] demonstrate an integrated approach for improving energy efficiency of manufacturing process chains. Hawer et al. [72] develop a process model taking into account data-based interdependencies in factory planning and adopted a modular approach, including one module respecting the factor building. Dallasega et al. [4] investigated Industry 4.0 as an enabler of proximity for construction supply chains within a systematic literature review. The above-mentioned research is remarkable; however, it fails to fully incorporate building design. Based on the conducted research on building level, several authors proposed models concentrating on the industrial building itself. Kovacic et al. [34] developed an economic and environmental life-cycle analysis tool for facade-systems of industrial buildings and state that long-term horizons in the decision-making process are necessary. Heravi et al. [59] focused on social, economic and environmental aspects of industrial buildings and developed a MCDM framework for selection of optimized sustainable industrial building options. Cuadrado, et al. [81] proposed a MCDM sustainability assessment of industrial buildings including environmental, economic and social factors, as well as other factors (employee safety, corporate image), however neglect production processes. Chen et al. [39] integrate sustainability into the factory planning process, developing a model describing relations between factory buildings, manufacturing equipment, sustainability aspects and process planning. Bleicher et al. [37] proposed a co-simulation tool for predicting the energy demand of production facilities in early design stage, integrating sub-systems and Chinese et al. [82] used a multi-criteria analysis to select space-heating systems in industrial buildings. Gourlis and Kovacic [38] analyzed the building envelope refurbishment of an existing industrial facility using BIM and identify critical parameters affecting the energy performance. The above-presented research on optimization and decision support in IIBD is remarkable, yet it focuses on either production system or building optimization and neglects a holistic approach.

In summary, BIM, digital design and optimization methods for IIBD are already used in isolated cases, but there is still a lack of interoperability and data consistency between discipline-specific tools. A large number of interrelated processes and data, sub-processes and stakeholders involved in different project phases make IIBD complex. Holistic industrial building design requires maximum stakeholder and software integration, including a vast amount of parameters from production planning, structural design, architecture and energy planning already at early design stage. However, few researchers have examined methods that explore holistic design guidance in IIBD for the needs of Industry 4.0.

This paper is addressing the collection of data to develop a formal design guideline for IIBD towards the requirements of Industry 4.0, focusing on the three levels of: objectives, technical parameters and the planning process in IIBD. The data were gathered trough a multiple case study based on expert interviews. The literature research provided us with numerous parameters and the latest findings in industrial building design and production planning to expand and complete the developed design guideline. The followed methodology is described in the next section.

\section{Methodology}

The employed methodological approach is based on social empirical research, conducting a comprehensive literature review and a case study methodology with expert interviews [83]. The literature review served to analyze best practices in industrial building 
design and production planning, while the multiple case study with expert interviews was performed to close the knowledge gaps of the researchers and to generate technical and process knowledge [84]. Figure 1 presents the overview of the research methodology and the research outputs.

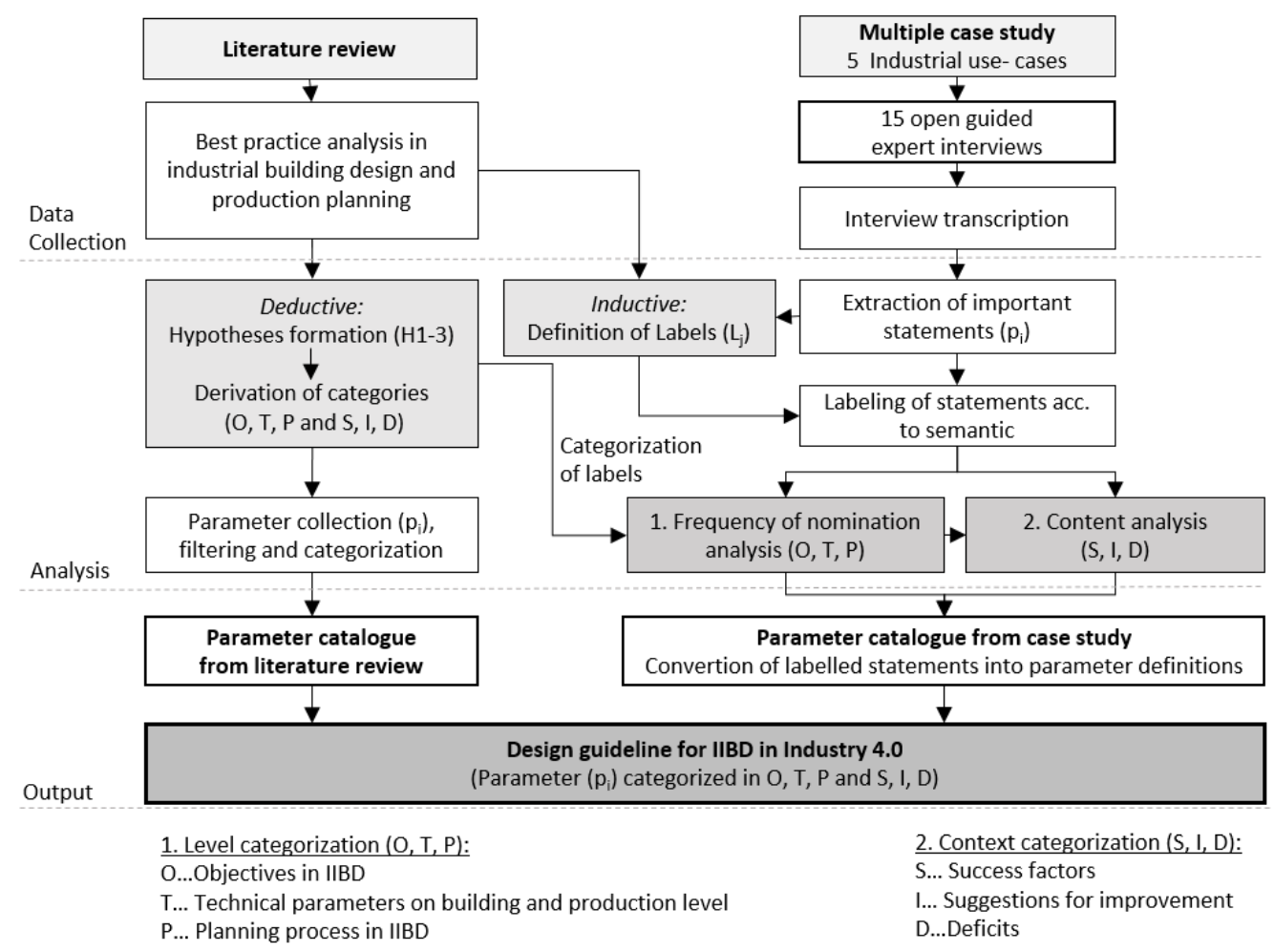

Figure 1. Overview of the research methodology and scope of the paper.

Based on the literature review findings, the three hypotheses (H1-Flexibility, H2Structural design, H3 - Integrated computational models), presented in Section 1, were formulated and two categorization schemes (level and context categorization) defined. The categorization served us for analysis, filtering and classifying the obtained parameters into a transparent structured design guideline.

The level categorization $(\mathrm{O}, \mathrm{T}, \mathrm{P})$ arranges the parameters into the three categories of objectives level $(\mathrm{O})$ resulting from hypothesis 1 , technical parameters level $(\mathrm{T})$ formed from hypothesis 2 and planning process level (P) following hypothesis 3.

- O. Objectives in IIBD.

- T. Technical parameters on industrial building and production level.

- P. Priorities, potentials and problems in the planning process of industrial buildings.

The context categorization (S, I, D) describes in which context the parameters are identified. Through a content analysis of the interviews conducted [84], the parameters are classified according to the expert statements into the categories of Success factors (S), Suggestions for improvement (I) and Deficits (D).

The interview evaluation followed the procedure of Bogner et al. [84] by labelling of the received statements in order to develop a plausible and theoretically sophisticated reading of expert practices in the best possible directness. Thereby, after the transcription of the interviews, a list of all relevant statements was compiled in a Microsoft Excel spreadsheet. According to the semantic structure and core content, each statement was allocated to a label $\left(\mathrm{L}_{\mathrm{j}}\right)$, following an inductive "bottom-up" logic, see Section 3.1. The labelling of text fragments was necessary to make individual statements countable and comparable. First, a frequency of nomination analysis was carried out, sorting the labels by 
number of mentions per stakeholder. Second, a content analysis was conducted to describe in which context the labelled statements were identified.

For the design guideline development, the labelled statements were concretized into parameter definitions $\left(\mathrm{p}_{\mathrm{i}}\right)$. The parameter catalogue is structured in matrix form, classifying each parameter to one level and one context category (see Equation (1)). Equation (1) describes a parameter whose underlying statements were labelled within the label number 17, were made on planning process level and were named in context of a success factor. Finally, the interview analysis results were verified and extended by the literature research results, completing the design guideline for IIBD in Industry 4.0 which is categorized into O, T, P and S, I, D.

$$
p_{i} \rightarrow \text { Label }_{j} \rightarrow\left(\begin{array}{cc}
\mathrm{O} & \mathrm{S} \\
\mathrm{T} & \mathrm{I} \\
\mathrm{P} & \mathrm{D}
\end{array}\right) ; p_{8} \rightarrow \text { Label }_{17} \rightarrow\left(\begin{array}{cc}
0 & 1 \\
1 & 0 \\
0 & 0
\end{array}\right)
$$

\subsection{Case Study Design and Definition of Labels}

A multiple case study methodology with expert interviews was carried out in this study [83]. The interviews conducted with experts from the industry allowed the mapping of discipline-specific knowledge, needs and requirements in industrial building design practice focusing on Industry 4.0 aspects. Thereby, fifteen experts (five building owners, three architects, three structural engineers and four production planners) involved in five real industrial building projects, were interviewed via guided, open-ended interviews. Regarding the number of use cases to be investigated, we followed the recommendation of four to ten use cases to study [83]. The use cases were selected because they had the best accessibility to leading stakeholders. In industrial context, the availability of data is difficult because of industrial espionage. In this study, our industrial partners agreed to provide data and information from five real use cases from the production sector. When selecting the use cases, it was important to examine different types of production so as not to obtain results only for a specific production sector. Table 1 presents the use-cases involved in the study and the number of conducted expert interviews per use-case and stakeholder.

Table 1. Overview of the use cases and conducted expert interviews.

\begin{tabular}{|c|c|c|c|c|c|}
\hline Use Cases & A & B & $\mathrm{C}$ & D & E \\
\hline Production Type & Cleanroom-Chip & Metal processing & Metal processing & Food production & Food production \\
\hline Gross Floor Area $\left[\mathrm{m}^{2}\right]$ & 60,000 & 16,000 & 9000 & 24,000 & 4600 \\
\hline Total Building Costs [mil] & n.m. & 45 & 17 & 50 & n.m. \\
\hline Interviews per Use-Case & A & B & $\mathrm{C}$ & D & $\mathrm{E}$ \\
\hline 1 Building Owner & 1 & 1 & 1 & 1 & 1 \\
\hline 2 Architect & 0 & 1 & 1 & 0 & 1 \\
\hline 3 Structural Engineer & 0 & 0 & 1 & 1 & 1 \\
\hline 4 Production Planner & 0 & 1 & 1 & 1 & 1 \\
\hline
\end{tabular}

The guided interviews were supported by an open-ended questionnaire. The questionnaire included questions about general personal and company information, about the specific use-cases and about the planning process, goals and potentials in Industry 4.0. The questionnaire structuring and the contained questions are presented in Table 2.

After the transcription of the interviews, the expert statements were allocated to labels in order to analyze the interview results. Table 3 presents the defined labels with given examples of involved statements. The labels were grouped according to the level categorization of $\mathrm{O}, \mathrm{T}, \mathrm{P}$. On objectives level eight labels, on technical parameters level four labels and on planning process level ten labels were defined. 
Table 2. Questionnaire for the guided, open-ended expert interviews within the case study.

\section{Questions about General Personal and Company Information:}

1.1 What discipline/profession do you belong to/what role do you usually play in projects/years of experience?

1.2 Information about the company: fields of activity/company size/general project sizes/production type.

\section{Questions about the Use-Case:}

2.1 Company organization: size and organization of team/process organization and coordination/interfaces.

2.2 Contract form and commissioning within the project/criteria for commissioning.

2.3 Describe the planning process: working methods/application of digital tools/data collection and exchange

2.4 Describe the communication, collaboration and exchange of information (internally and externally) within the project.

2.5 Describe the main deficits and potentials in the projects planning process and interdependencies to other disciplines.

\section{Questions about Ideal Industrial Building Design Processes and Goals of Industry 4.0:}

3.1 Describe an ideal planning process and requirements of successful industrial building design for Industry 4.0. 3.2 What are key criteria and goals in industrial building design for the needs of Industry 4.0?

3.3 What are successful (future) digitization and knowledge management strategies in industrial building design?

Table 3. Overview of the label structuring per level categorization for analysis and highlights some statement examples received from the expert interviews.

\begin{tabular}{|c|c|}
\hline O. Labels & O. Objectives Level (e.g., Statements) \\
\hline Architectural quality & Aesthetic, functional, sustainable buildings \\
\hline Communication & Layouts which allow communication, collaboration and information flow \\
\hline Costs & Design to cost, minimize life cycle costs \\
\hline Durability & Robust buildings which can accommodate to changes, robust structures and materials \\
\hline Expandability & Plan growth areas in buildings, production and on properties \\
\hline Flexibility & Allow reconfigurable machine layouts in buildings (e.g., maximum span width) \\
\hline Lean Production & Enable constant production re-organization, pull principle, no reservation of capacities \\
\hline Energy Efficiency & Efficient heating and cooling, facade and roof insulation, sound insulation, draught \\
\hline T. Labels & T. Technical Parameters Level (e.g., Statements) \\
\hline Architecture & Floor plan design, room height, daylight, building envelope, traffic areas for production \\
\hline Building Service Equ. & Type, geometry and position of media supply, installation level, fire safety \\
\hline Production Planning & Type of production line (U-,S-, I production), production process, machine types and layout \\
\hline Structural Design & Column axis grid, foundation, structural type, span width, material, consider retrofitting loads \\
\hline P. Labels & P. Planning Process Level (e.g., Statements) \\
\hline 3D Planning & 3D planning and models for better collision checks, presentation and visualization support \\
\hline Commissioning & Architectural contests, commissioning of a general planner, consulting for client \\
\hline Communication & Early communication of client and stakeholder goals, standardized and open communication \\
\hline Design Team & Small, competent and versatile design teams, BIM manager \\
\hline Flexibility in Design & Integration of flexibility measures for decision support, create awareness for flexible design \\
\hline Early Design Stage & Early integration of construction firm and structural design, early definition of goals \\
\hline Integrated Design & Process and model integration, follow joint goals, quick feedback loops \\
\hline Interfaces & Different interfaces, data and software between building and production planning \\
\hline Requirement planning & Demand planning and holistic understanding of processes, definition of expectations \\
\hline Software & Challenging model and data exchange with other disciplines, no holistic design platform \\
\hline
\end{tabular}

\section{Case Study Analysis}

In this section, we present the results of the frequency of nomination analysis and the content analysis of the statements received from the expert interviews.

\subsection{Frequency of Nomination Analysis}

After the interview transcription, followed by the extraction and summarization of the relevant statements and the subsequent assignment of the statements to a label, an 
analysis of the labels by frequency of nomination was carried out. The analysis results are organized according to the labelling structure into objectives, technical parameters and planning process level. The frequency of nomination $(\mathrm{F})$ of a label is determined by the total number of statements allocated to a label divided by the total sum of labelled statements in the respective $\mathrm{O}, \mathrm{T}$, or $\mathrm{P}$ category, see equation 2 . Furthermore, to obtain an indication of the average mentions of the label per interviewed expert $(n=15)$, the mean value $(\mu)$ is determined, see equation 3. The Table 2 (for O), Table 3 (for T) and Table 4 (for $\mathrm{P})$ present the number of statements made according to a label per stakeholder, $\mathrm{F}$ and $\mu$.

$F_{i}=\left(\right.$ Sum of all statements allocated to a label $\left.\mathrm{L}_{\mathrm{i}}\right) /($ Sum of all labelled statements in a category $(\mathrm{O}, \mathrm{T}, \mathrm{P}))$

$\mu_{\mathrm{i}}=\left(\right.$ Sum of all statements allocated to a label $\left.\mathrm{L}_{\mathrm{i}}\right) /($ Sum of all interviewed experts $(n=15))$

\subsubsection{O. Objectives Level}

Table 4 presents the frequency of nomination analysis results on objectives level categorized per stakeholder. The results reveal that most statements in the category of objectives in IIBD are related to flexibility $(\mathrm{F}=42 \%)$. In particular, the building owners highlight the importance of designing flexible buildings and production systems. The analysis shows that the second most nominated objective is expandability $(\mathrm{F}=14 \%)$ followed by lean production $(\mathrm{F}=12 \%)$ and architectural quality $(\mathrm{F}=11 \%)$. Communication counts five statements $(\mathrm{F}=8 \%)$ and costs four statements $(\mathrm{F}=6 \%)$, both mentioned from building owners and production planners. The energy efficiency $(\mathrm{F}=5 \%)$ and the durability $(\mathrm{F}=3 \%)$ are further objectives in IIBD. The interviewed architects consider flexibility, expandability and the architectural quality as main objectives, while the structural engineers seek for flexibility and increased durability of the supporting structure in design. The production planners define lean production, flexibility and expandability as goals in IIBD.

Table 4. O. Objectives level: Frequency of nomination (F) of the labels on objective level categorized per stakeholder.

\begin{tabular}{|c|c|c|c|c|c|c|}
\hline Label (O) & $\begin{array}{l}\text { Building } \\
\text { Owner }\end{array}$ & Architect & $\begin{array}{c}\text { Structural } \\
\text { Engineer }\end{array}$ & $\begin{array}{l}\text { Production } \\
\text { Planner }\end{array}$ & $\mathbf{F}$ & $\mu$ \\
\hline Flexibility & 18 & 4 & 2 & 3 & $42 \%$ & 1.8 \\
\hline Expandability & 5 & 2 & 0 & 2 & $14 \%$ & 0.6 \\
\hline Lean Production & 4 & 0 & 0 & 4 & $12 \%$ & 0.5 \\
\hline Architectural Quality & 4 & 2 & 0 & 1 & $11 \%$ & 0.5 \\
\hline Communication & 4 & 0 & 0 & 1 & $8 \%$ & 0.3 \\
\hline Costs & 3 & 0 & 0 & 1 & $6 \%$ & 0.3 \\
\hline Energy Efficiency & 2 & 0 & 0 & 1 & $5 \%$ & 0.2 \\
\hline \multirow[t]{2}{*}{ Durability } & 1 & 0 & 1 & 0 & $3 \%$ & 0.1 \\
\hline & & $\Sigma$ & Statements $(n)$ & 65 & $100.00 \%$ & \\
\hline
\end{tabular}

\subsubsection{T. Technical Parameters Level}

Table 5 presents the frequency of nomination analysis results on technical parameters level. Twelve out of thirty-one statements can be allocated to the label of structural design $(\mathrm{F}=39 \%)$, followed by eleven mentioned parameters within the label architectural design $(\mathrm{F}=35 \%)$. Building service equipment parameters are especially highlighted by building owners $(\mathrm{F}=13 \%)$ and production planning parameters $(\mathrm{F}=13 \%)$ are mentioned by building owners and production planner. Building owners relate five statements to parameters in structural design for flexible industrial buildings. The architects see significant parameters in industrial building design within the label architecture (number of mentions $(n)=2$ ) and structural design $(n=1)$. Structural engineers bring up five statements, including structural 
design parameters followed by two architectural design parameters. The production planners aim for free floor plans in architectural design $(n=5)$ to allow reconfiguration of production layouts in production planning $(n=3)$.

Table 5. T. Technical Parameters: Frequency of nomination (F) of the labels on parameters level categorized per stakeholder.

\begin{tabular}{|c|c|c|c|c|c|c|}
\hline Label (T) & $\begin{array}{l}\text { Building } \\
\text { Owner }\end{array}$ & Architect & $\begin{array}{c}\text { Structural } \\
\text { Engineer }\end{array}$ & $\begin{array}{l}\text { Production } \\
\text { Planner }\end{array}$ & $\mathbf{F}$ & $\mu$ \\
\hline Structural Design & 5 & 1 & 6 & 0 & $39 \%$ & 0.8 \\
\hline Architecture & 2 & 2 & 2 & 5 & $35 \%$ & 0.7 \\
\hline Building Service Equipment & 4 & 0 & 0 & 0 & $13 \%$ & 0.3 \\
\hline \multirow[t]{2}{*}{ Production Planning } & 1 & 0 & 0 & 3 & $13 \%$ & 0.3 \\
\hline & & $\Sigma$ & Statements $(n)$ & 31 & $100.00 \%$ & \\
\hline
\end{tabular}

\subsubsection{P. Planning Process Level}

The frequency of nomination analysis results on planning process level (see Table 6) demonstrate that most statements refer to the focus on the early design stage $(\mathrm{F}=16 \%)$ for successful IIBD processes. The second most nominations mention sufficient interfaces $(\mathrm{F}=14 \%)$ and the constellation and skills of the design team $(\mathrm{F}=13 \%)$. The applied software environment $(\mathrm{F}=13 \%)$ is considered as another significant aspect among all stakeholders. An integrated design approach $(\mathrm{F}=12 \%)$ was mentioned multiple times from building owners, structural engineers and production planners. Furthermore, flexibility in design $(10 \%)$ and 3D Planning $(\mathrm{F}=7 \%)$ are stated as requirements for effective industrial building design processes. Finally, requirement planning $(\mathrm{F}=6 \%)$ and commissioning $(\mathrm{F}=3 \%)$ do affect industrial building design processes according to the provided statements. The building owners mostly relate their statements on planning process level to interfaces $(n=8)$, integrated design $(n=8)$ and flexibility in design $(n=7)$. Architects see the focus on early design stage $(n=6)$ and the software environment $(n=5)$ as major aspects for a projects' successes. The structural engineers make statements regarding the labels interfaces $(n=12)$ and the design team constellation $(n=11)$, followed by the focus on early design stage $(n=6)$ and software $(n=6)$. The most statements from production planners refer to the focus in early design stage $(n=8)$, software $(n=7)$ and flexibility in design $(n=7)$.

Table 6. P. Planning process level: Frequency of nomination (F) of the labels on process level categorized per stakeholder.

\begin{tabular}{|c|c|c|c|c|c|c|}
\hline Label (P) & $\begin{array}{l}\text { Building } \\
\text { Owner }\end{array}$ & Architect & $\begin{array}{c}\text { Structural } \\
\text { Engineer }\end{array}$ & $\begin{array}{l}\text { Production } \\
\text { Planner }\end{array}$ & $\mathbf{F}$ & $\mu$ \\
\hline Focus Early Design Stage & 6 & 6 & 6 & 8 & $16 \%$ & 1.7 \\
\hline Interfaces & 8 & 1 & 12 & 2 & $14 \%$ & 1.5 \\
\hline Design Team & 1 & 4 & 11 & 5 & $13 \%$ & 1.4 \\
\hline Software & 3 & 5 & 6 & 7 & $13 \%$ & 1.4 \\
\hline Integrated Design & 8 & 1 & 5 & 6 & $12 \%$ & 1.3 \\
\hline Flexibility in Design & 7 & 0 & 2 & 7 & $10 \%$ & 1.1 \\
\hline 3D Planning & 4 & 2 & 3 & 2 & $7 \%$ & 0.7 \\
\hline Communication & 3 & 4 & 2 & 0 & $6 \%$ & 0.6 \\
\hline Requirement Planning & 2 & 4 & 0 & 4 & $6 \%$ & 0.7 \\
\hline \multirow[t]{2}{*}{ Commissioning } & 1 & 3 & 0 & 0 & $2 \%$ & 0.3 \\
\hline & & $\Sigma$ & Statements $(n)$ & 161 & $100.00 \%$ & \\
\hline
\end{tabular}




\subsubsection{Summary of the Frequency of Nomination Analysis}

In total, 65 statements were identified as objectives, 31 statements were allocated to technical parameters and 161 statements were recognized regarding the planning process. Figure 2 presents the relative frequency of nominations of the labels in the form of pareto front diagrams. The diagrams contain both bars and lines, where the individual labels are represented in descending order by bars, and the cumulative total of the sample is represented by the curved red line. The pareto principle can be seen as a powerful decisionmaking criterion and states that the bulk of problems are the result of a few factors. Thus, to gain the largest benefits for quality and productivity improvement, the focus should be on the "vital few" as opposed to the "trivial many" [85]. The first diagram presented in Figure 2 demonstrates that the largest frequency of occurrence for objectives in IIBD is on the label flexibility (27 statements) with the largest bar, followed by expandability with 9 statements. The two most vital labels on technical parameters level are structural design with 12 statements and architectural parameters with 11 coded statements. On the planning process level, the vital statements on the pareto front are the focus on early design stage (26 statements), interfaces ( 23 statements), the design team (21 statements), software (21 statements) and integrated design (20 statements).

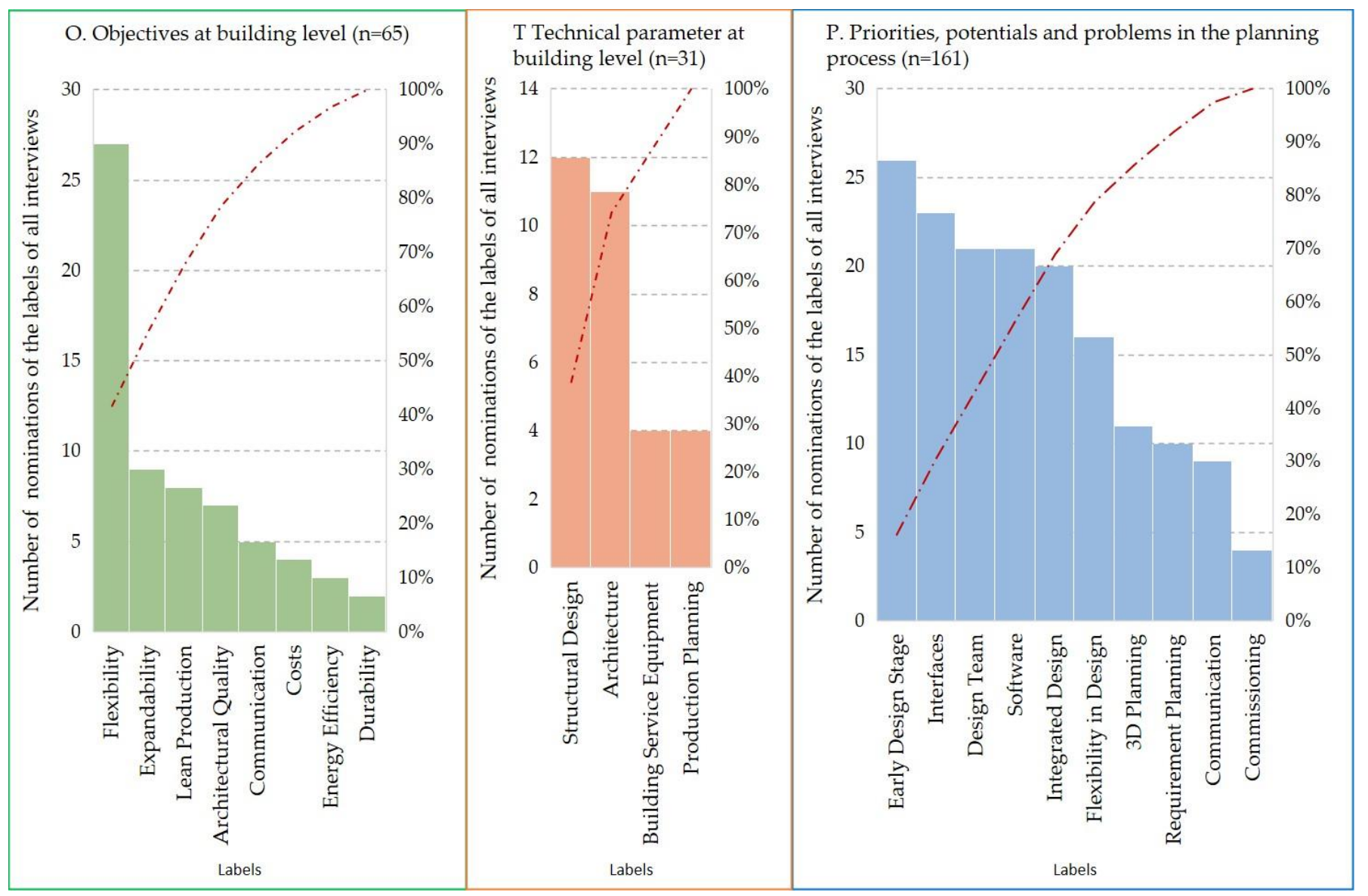

Figure 2. Frequency of nomination analysis results of the labelled expert statements on objectives, technical parameters and planning process level in form of pareto front diagrams. The labels are represented in descending order by bars and the cumulative total of the label sample is represented by the curved red line.

\subsection{Content Analysis}

This section presents the results of the content analysis, examining the context in which the statements were made and to determine whether a label belongs to a success factor, a suggestion for improvement or a deficit. The analysis is a deductive conclusion 
and does not represent an evaluation. A statement with a corresponding label in connection with i.e., a deficit, cannot assure that it is actually a deficit for all stakeholders as naturally goals can be conflicting among different stakeholders. Table 7 presents the content analysis results and the deductive categorization of the labels sorted by the mean value of the label mentioned per stakeholder.

\subsubsection{S. Success Factors}

The labels, thus included parameters extracted from the statements, identified as success factors have the potential to meet objectives and increase performance improvement in IIBD for Industry 4.0. On objectives level, the statements related to flexibility, lean production, architectural quality and communication were recognized as potential success factors. The content analysis of the statements on technical parameters level shows that the labels structural design and production planning can be defined as success factors. The load-bearing structure and production systems have a high impact on flexibility, thus are important prerequisites for sustainable industrial building design. The content analysis of the statements allocated to the labels on planning process level reveals that the labels focus on early design stage, integrated design and 3D planning were made in context to a success factor.

\subsubsection{Suggestions for Improvement}

The content analysis on objective level reveals that suggestions for improvement level are stated within the labels of expandability, costs, durability and energy efficiency. The expert interviews reveal that the expandability of building and production areas is an important goal but often not realized in practice yet. Most of the time "slim fit" buildings are build, according to current production demands. If the design team would plan for growth areas (i.e., build one more axis grid) the business growth could correlate to the building service life. The statement analysis further reveals that currently buildings are not designed for sufficient robustness but increasing the durability of the supporting structure would allow better adaption to different use scenarios.

According to the content analysis on a technical parameters level, the architectural parameters have potentials for improvement, suggesting to focus on the maximization of the inner room height and to design the building for the current and future machine and production layout demands. In addition, the design of industrial buildings could be improved by making them suitable for automation processes, i.e., enabling driverless systems by providing more robust floors and avoiding steep ramps and narrow paths. The analyzed statements suggest an improvement of the building service parameters. It is recommended to always decouple them from the building structure to ensure a flexible media flow, thus allow flexible machine layouts. In addition, the media supply should be oversized for future retrofitting.

Suggestions for improvement on planning process level concern the design team. The design team should work with smaller teams and versatile team constellations and need precise coordination. In addition, it is recommended that all involved stakeholders must be familiar with the holistic project goals, pursuing them throughout the whole planning process to overcome silo thinking. The opinion among the interviewed experts is that currently flexibility measurements are not integrated into the planning process. However, creating awareness for flexibility to all stakeholder and providing flexibility measures as decision support at early design stage could improve the performance of a building in long term. Furthermore, the experts state that the communication culture must be improved and suggest standardized, open communication processes to improve the design process, thus project outcome.

\subsubsection{Deficits}

The content analysis reveals four deficits in current IIBD practice. The interfaces between building and production planning and from 2D to 3D software are inefficient 
and related with data loss. Furthermore, different stakeholders work with different levels of detail (LOD) and different closed software systems, making the data and information exchange challenging. The lack of a holistic factory design software to be able to see the effects of a planning decision on other disciplines design (i.e., allow quick collision checks) was highlighted by the experts. Moreover, the interview participants see deficits in requirement planning and commissioning. Usually, not all planning stakeholders are involved in the planning process from the very beginning, starting with the master planning. In addition, there is a lack of early communication and awareness of joint project goals that all planning disciplines should adhere to and follow throughout design and construction.

Table 7. Content analysis results: The table presents the context categorization of the labels according to the core content of the included statements into success factors, suggestions for improvement and deficits, sorting them by the mean value of the label mentioned per stakeholder.

\section{S. Success Factors}

(Level) Label

(O.) Flexibility

(P.) Early Design Stage

(P.) Integrated Design

(T.) Structural Design

(P.) 3D Planning

(O.) Lean Production

(O.) Architectural Quality

(O.) Communication

(T.) Production Planning

(Level) Label

(P.) Design Team

(P.) Flexibility in Design

(T.) Architecture

(P.) Communication

(O.) Expandability

(T.) Building Service Equ.

(O.) Costs

(O.) Durability

(O.) Energy Efficiency

(Level) Label

(P.) Interfaces

(P.) Software

(P.) Requirement Planning

(P.) Commissioning
Summary

$\mu$

Flexible buildings which allow reconfigurable layouts and processes $\quad 1.80$ Integration, collaboration and definition of goals already at early design stage $\quad 1.73$

Stakeholder cooperation throughout all stages; Integration of building and production $\quad 1.33$

Design of over-capacity of the structure to enable retrofitting and expansion $\quad 0.80$

3D planning for collision checks (structure, media, machines) and visualization $\quad 0.73$

Enable reconfiguration of machines; No reservation of capacities; Pull principle $\quad 0.53$

$\begin{array}{ll}\text { Design of aesthetic, representative, sustainable and functional buildings } & 0.47\end{array}$

Communication should be enabled throughout the whole building and layout $\quad 0.33$

Respect production process in building design; Production flow; Machine types/size $\quad 0.27$

\section{Suggestions for Improvement}

Summary

Small, competent and versatile project team; Software know-how; Follow joint goals $\quad 1.40$

Early integration of flexibility measures; Create awareness for flexibility $\quad 1.07$

Floor plan design; Room height; Design for automation; path and walkway planning $\quad 0.80$ through the production process

Improve communication culture; Standardized and open communication; Mediation $\quad 0.60$

Expansion areas in building, production and on property to enable business growth $\quad 0.53$

Customization of media supply; Flexible media flow; Decouple media and structure $\quad 0.27$

Design to cost; Respect and minimize life-cycle costs in design stage $\quad 0.27$

Design robust buildings/structures to enable changes; Prolong building service life $\quad 0.20$

Efficient air supply and exhaust; Cooling/heating; Sound insulation; Enclosure system $\quad 0.13$

\section{Deficits}

Summary

$\mu$

Inefficient interfaces from 2D to 3D and building to production models; Data loss at 1.53

exchange; Different level of details

Improve discipline-specific data exchange; No holistic factory design software $\quad 1.40$

Early communication of requirements and goals for a holistic process understanding $\quad 0.67$

Architectural competitions; early commission of all stakeholders; General planner $\quad 0.27$

\section{Result-Design Guideline for IIBD in Industry 4.0}

Hence, as final result, we summarize and merge the case study and literature review findings and present a design guideline for IIBD in Industry 4.0. Therefore, the expert statements were abstracted into parameter definitions and the design guideline for IIBD in Industry 4.0 was developed in the form of a categorized parameter catalogue in a Microsoft Excel spreadsheet. The parameter catalogue maintains the structuring of the level categorization $(\mathrm{O}, \mathrm{T}, \mathrm{P})$, the context categorization (S, I, D) and the label allocation.

In total, the design guideline consists of 129 identified parameters. Of those, 36 parameters were allocated to objectives, 24 to technical parameters and 69 to the planning process. Table 8 presents an exemplary structure of the design guideline table, where each parameter in $\mathrm{O}, \mathrm{T}, \mathrm{P}$ is associated with a label and a context. The parameter value corre- 
sponds to the content analysis of the statements of the interviews and/or the conclusion of the literature sources.

Table 8. Exemplary table extraction of the design guideline for IIBD in Industry 4.0. The table shows the structuring of the parameters: First, the parameters are categorized into objectives, technical parameters and process level in adherence to the label assignment. Second, the parameters are indicated as a success factors, a suggestions for improvement or a deficits.

\begin{tabular}{|c|c|c|c|c|c|c|}
\hline \multicolumn{7}{|c|}{ Design Guideline for IIBD in Industry 4.0} \\
\hline \multicolumn{5}{|c|}{ O. Objectives in integrated industrial building design. } & \multicolumn{2}{|c|}{ Data source } \\
\hline Label & Context & $\mathrm{H}$ & Parameter & Value & Use-Case/Expert & Literature \\
\hline \multirow{2}{*}{ Flexibility } & \multirow[t]{2}{*}{$\mathrm{S}$} & O1 & $\begin{array}{l}\text { Column free- zones in } \\
\text { production area }\end{array}$ & $\begin{array}{l}\text { Minimize amount of columns } \\
\text { inside production layout area }\end{array}$ & {$[\mathrm{C} 1]$} & {$[19,41]$} \\
\hline & & $\mathrm{O} 2$ & Flexible machine layout & Spatial change of machines & [B1] [C1] [C4] & {$[19,52,63]$} \\
\hline \multirow[t]{2}{*}{ Expandability } & \multirow[t]{2}{*}{ I } & $\mathrm{O} 20$ & Maximize growth areas & $\begin{array}{l}\text { Expansion possibility through } \\
\text { predefined growth areas in } \\
\text { production, building, property }\end{array}$ & $\begin{array}{c}{[\mathrm{D} 1][\mathrm{E} 4][\mathrm{C} 1]} \\
{[\mathrm{C} 4]}\end{array}$ & {$[19,41,81]$} \\
\hline & & $\mathrm{O} 21$ & $\begin{array}{l}\text { Pre-planning of } \\
\text { expansion interfaces }\end{array}$ & $\begin{array}{l}\text { Provide and pre-design } \\
\text { interfaces for future expansions }\end{array}$ & [D4] & [23] \\
\hline \multicolumn{7}{|c|}{ T. Technical parameters on industrial building level } \\
\hline \multirow{2}{*}{$\begin{array}{l}\text { Structural } \\
\text { Design }\end{array}$} & \multirow{2}{*}{ S } & $\mathrm{T} 1$ & Foundation & $\begin{array}{l}\text { Oversize foundation for future } \\
\text { loads }\end{array}$ & [B2] & {$[19,63]$} \\
\hline & & $\mathrm{T} 2$ & Girder span width & Maximize column grid distance & [C1] & {$[19,63]$} \\
\hline \multirow{2}{*}{ Architecture } & \multirow{2}{*}{ I } & $\mathrm{T} 7$ & Free inner room height & $\begin{array}{l}\text { Surplus of room height for } \\
\text { retrofits }\end{array}$ & [B4] [E1] [E3] & {$[19,41,60]$} \\
\hline & & $\mathrm{T} 8$ & Floor plan configuration & $\begin{array}{l}\text { Prefer orthogonal floor plans } \\
\text { and avoid special shapes }\end{array}$ & [E5] & {$[38,41]$} \\
\hline \multicolumn{7}{|c|}{ P. Priorities, potentials and problems in the planning process of industrial buildings } \\
\hline \multirow{2}{*}{$\begin{array}{l}\text { Focus early } \\
\text { design stage }\end{array}$} & \multirow{2}{*}{ S } & P1 & Early needs assessment & $\begin{array}{c}\text { Early integration of stakeholder } \\
\text { needs }\end{array}$ & [B2] & {$[1,11,77]$} \\
\hline & & $\mathrm{P} 2$ & Early BIM Collaboration & $\begin{array}{l}\text { Holistic BIM model at early } \\
\text { design stage }\end{array}$ & [C3] [D3] & {$[1,27]$} \\
\hline \multirow{2}{*}{ Interfaces } & \multirow{2}{*}{$\mathrm{D}$} & P15 & Definition of Interfaces & $\begin{array}{l}\text { Enable sufficient interfaces for } \\
\text { data and model exchange }\end{array}$ & [C2] & {$[13,52,73]$} \\
\hline & & P16 & Digital language and LOD & $\begin{array}{l}\text { Avoid different digital speeches } \\
\text { (decide if 2D or 3D) }\end{array}$ & [D1] & {$[11,27,66,67]$} \\
\hline \multirow{2}{*}{ Design Team } & \multirow{2}{*}{ I } & P27 & Knowledge transfer & $\begin{array}{l}\text { Experienced team members } \\
\text { with a lot of personal } \\
\text { contact/collaboration }\end{array}$ & [E3] & {$[55,56,68,86]$} \\
\hline & & $\mathrm{P} 28$ & Team members & $\begin{array}{c}\text { Deployment of people with } \\
\text { visions and increased experience } \\
\text { level }\end{array}$ & [C3] & {$[11,27,56,86]$} \\
\hline
\end{tabular}

The following is a summarized description of the design guideline parameters identified from the case study and literature review:

\subsection{Objective Level Parameters}

In total, 36 parameters could be identified within the eight labels on objectives level:

Flexibility was identified as the primary objective in IIBD for the interview participants and includes parameters such as reconfigurable machine layouts, flexible working stations and production areas that provide puffer zones. Further flexibility-related goals are a maximum free gross floor area, maximum span width with no columns inside the production area, a maximum inner hall height and the maximum process variability to enable multiple different production process scenarios in the building. Building service equipment, which is intelligently adaptable to changing machine layouts, modular construction and facades with increased openings to allow the latter adding of machines were also mentioned as objectives to increase flexibility. 
Architectural quality related objectives were identified as aesthetics, maximum exposure surfaces to increase the working atmosphere and the application of sustainable, high-quality materials within design. Furthermore, a functional shape and modularity in construction are important goals for the experts towards increased architectural quality.

Expandability-linked objectives for the interviewed stakeholders are the maximization of growth areas and surplus of available floor space for expansion possibility of the building, the production and the property. Expansion should be designed with the possibility to extend production during full operation. Moreover, stakeholders recommend an early planning of expansion interfaces (i.e., expansion possibilities of structural and technical building service equipment) and evaluating the expansion capacity of the property already when purchasing new land.

Lean production was identified as the main goal for the production planners, aiming for a harmonization of need and demand in production planning. Thereby, avoiding intermediate storage in the production flow and separating value creation from logistic processes. The production capacity should follow the pull principle, avoiding capacity peaks.

Communication must be promoted throughout the whole layout and building. For effective communication and collaboration, the interview participants recommend the optimization of the positioning of building and production units. The goal is to locate production and office buildings as close as possible.

Cost goals should follow the concept design to cost and the main objective mentioned by the experts is to minimize the life-cycle costs for improved economic performance.

Durability of the building can be increased by a regular, robust and over-dimensioned load-bearing structure. The load-bearing structure's capacity must be designed to carry future loads for retrofitting or reconfiguration of production systems. Resistant buildings aim to reduce greenhouse gas emissions and the resource consumption by extending the buildings service life, thus avoiding rescheduling or demolition.

Energy efficiency can be improved by optimization of the air supply and exhaust, the insulation of the façade and roof systems and the whole building envelope system with window openings.

\subsection{Technical Parameters}

In total, 24 parameters were defined within the four labels on technical parameters level:

Structural design-related technical parameters mentioned by the experts are the material and construction type, load-bearing system type, dimensioning and position of girder, foundations and columns and the lateral system type. Furthermore, to guarantee a surplus of the inner hall height, results in minimizing of the girder height. However, to be able to add future loads, an over dimensioning of the structural elements (foundation, columns and girder) for increased load-bearing capacity should be provided.

Architectural parameters for an IIBD are the floor plan reconfiguration (avoid special shapes and prefer orthogonal, rectangular shapes), the façade system type and the lightning/window type, thus position. Moreover, experts state to design the ramp and path situation within the building concerning reconfigurable and changing production processes. Furthermore, they suggest to plan the inner free room height with additional surplus than the current machine layout requires.

Building service equipment parameters received from the interviews are the type and dimensioning of the energy media supply, the fire protection system and the position, distribution and customizability of the utilities. Additionally, experts recommend decoupling the distribution of the media from the structural system.

Production planning related parameters suggested by the experts are the central merging of machine data, the production process flow and the production process layout. Moreover, the interview participants recommend respecting the position and dimension of machines and the working and maintenance area around the machines for the planning of space requirements. 


\subsection{Planning Process Parameters}

In total, 69 parameters were identified within the ten labels on planning process level:

The focus on early design stage label contains parameters, which are relevant for the early design stage in IIBD, including parameters such as early integration of structural design, machine layouts/sizes and different production process scenarios. Furthermore, the experts suggest carrying out an early need and goals assessment with all stakeholders and the early use and collaboration of Building Information Modeling (BIM) methods. The integration of all stakeholders including construction firms, already at master planning phase is recommended to improve the design process through increased transparency.

Interfaces related parameters mentioned by the stakeholders contain efficient interfaces amongst different stakeholder on process and model level, technological innovation integration and interoperability. Standardized exchange formats and a common digital language (decide if 2D or 3D) are prerequisites for efficient planning processes and require a well-defined coordination strategy, interface definitions and modeling guidelines. Furthermore, experts suggest the employment of a BIM-Manager.

Design Teams can improve the design process through a reliable project manager, an effective collaboration strategy and an increased experience level of the involved stakeholders. According to the experts, special discipline-specific knowledge should be exchanged and transferred through regular structured design meetings including all stakeholders. The interview partners suggest that the composition of the design team should be kept as small but versatile as possible.

Software environments in IIBD seek for the establishment of a holistic digital design platform and integrated digital models. The experts aim for software, which provides collision check and decision-making support between different domains to avoid multiple processing steps. The digital data transfer between discipline-specific software must be improved. The experts highlight the lack of a digital holistic factory design software.

Integrated design in industrial building design aims for close collaboration and data and information exchange between all disciplines in all project phases. Experts state that the integration of all disciplines needs sufficient process and model integration and should be also defined in contracts. Experts recommend a harmonization of production planning processes and models with building design processes and models.

Flexibility in design parameters mentioned by the interview participants relate to flexible design systems and flexible data exchange, the consideration of future developments already in early design stage, the awareness creation of flexibility amongst all stakeholders and the integration of flexibility measures for decision-making support.

3D planning should enable central collision checks of i.e., machines and building structure and improve visualization and presentation.

Communication related parameters in IIBD processes contain standardized communication procedures, communication of project reviews to learn from previous projects and the improvement of communication to build trust and open relationships between all stakeholders.

Requirement Planning is according to the expert statements essential in IIBD processes. The building owner needs to communicate goals and needs for the project success to all stakeholders already at requirement phase. A holistic project understanding and the process demands must be provided to all stakeholders for early order quality and joint commitment.

Commissioning is suggested by the experts to commission a general planner for improved holistic design. The interview participant recommend to balance the orders and to avoid one-sided commissioning relationships.

\section{Discussion}

Based on interviews with experts and analysis of literature, a novel set of parameters was identified. These parameters form a design guideline for IIBD in an Industry 4.0 environment. The analysis of the interviews reveal significant principles and opinions in 
industrial building design and enabled the definition of objectives, technical parameters and planning process requirements in IIBD. Moreover, the content analysis of the expert statements allowed the classification of the identified parameters into success factors, suggestions for improvement and deficits.

The results of the interviews emphasize the crucial role of flexibility for sustainable industrial building design. Flexibility is the single criterion that all stakeholders would share when identifying objectives in IIBD. Consistently with our Hypothesis 1, we found that the experts unanimously agree that flexible buildings must have the capability to enable reconfigurable machine layouts and changes in the production processes to avoid early rescheduling or demolitions. The prolongation of the buildings service life has a positive impact on sustainability. Implementing flexibility to improve sustainability has also been investigated in the field of manufacturing [15] and residential building design [17] while some researchers study sustainability indicators in industrial building design $[8,62,81]$. The lack of a consistent definition of flexibility metrics for IIBD calls for future research.

In accordance with the literature and our $\mathrm{H} 2$, the design parameters commonly recognized as success factors in IIBD mostly relate to the structural building system. Experts described parameters such as the material and load-bearing system type, the dimensioning and position of girders, foundations and columns, the lateral system type. Moreover, the stakeholders highlight the necessity to design structural elements with excess capacity in order to allow for future retrofitting. To enable reconfigurable and extendable machine layouts experts suggest to include surplus when designing the floor plan and determining the building height. Building owners and production planners see the integration of production planning parameters such as machine types, machine sizes and production planning layouts into building design as success factors. Results from previous studies matched some of the parameters obtained from the interviews, and found additional parameters such as modular production areas, specific utility routing requirements [19], sprinkler systems for fire safety [63], insulation values and solar collector coverage [61]. The results of this study complement previous research and combine discipline-specific parameters from building owners, structural design, architecture and production planning into one holistic framework. However, in this study, a gap arises in the fact that although research community is intensively investigating the energy performance of industrial buildings $[18,37,61,82]$ no energy or media supply planners were interviewed. In further research, energy planners will be included in the survey and the parameter catalogue expanded. Finally, although the interview and literature analysis reveal the importance of the load-bearing structure in IIBD, an industrial building design model focusing on structural performance optimization is lacking.

The most frequently mentioned criteria on the planning process level are the focus on the early design stage, integrated design and 3D planning. Those parameters are recognized as success factors by all professions. The study findings lead us to approve $\mathrm{H} 3$, that an integrated planning approach supported by powerful computational tools is required in IIBD practice. However, when identifying the main deficits in current industrial building design processes, the interviewed stakeholders agree that the software and interfaces currently available have major shortcomings. Several stakeholders propose the potential of BIM-related tools for IIBD, yet highlighting the lack of integrated digital design models. Interfaces from $2 \mathrm{D}$ to $3 \mathrm{D}$ and from building to production models either are lacking, inefficient or associated with data loss. The experts aim for software which enables collision checks and decision-making support to avoid multiple processing steps. Belated involvement of all planning stakeholders and the early definition of joint goals for a holistic project understanding are further identified deficits. The interviewees see improvement potential in the early involvement of experienced and versatile team members, the early integration of flexibility measures and a transparent communication and information culture. The findings on process level are in line with existing research, which recommends data integration to overcome point solutions [64] and highlights the potential of BIM for 
manufacturing [13]. In industrial building design, stakeholders have to deal with more complex interrelated planning parameters compared to the design of residential or public buildings. Hence, integration in factory design is difficult due to error-prone and complex interfaces between building and production planning and the lack of maturity models [27]. Advanced modeling and simulation technologies, including BIM, parametric modeling, cloud-based simulation, and optimization algorithms have the potential for automated generation, evaluation, and optimization of multiple building design options [69]. There is a gap of digital solutions for quantitative planning success evaluation and systematic decision support models in factory planning [28]. Hence, the design of flexible industrial buildings requires a powerful computational model for multi-objective design optimization that integrates interdependent parameters and supports interdisciplinary decision-making. Such a holistic model is currently lacking and is the subject of our future research.

\section{Conclusions}

In the course of this paper, a design guideline for flexible industrial buildings integrating Industry 4.0 requirements was presented in the form of a categorized parameter catalogue. The research goal was to develop a common terminology and guidance to describe efficient design parameters and approaches to integrate production planning and building design. The study differs from previous research on industrial building and production planning as it aims to analyze and incorporate discipline-specific knowledge from building owners, architects, structural engineers and production planners into one holistic framework. Interviewing fifteen experts of the aforementioned domains which were involved in five real industrial building projects, enabled the collection of $(\mathrm{O})$ objectives, $(\mathrm{T})$ technical parameters and $(\mathrm{P})$ planning process requirements in IIBD for Industry 4.0. Each defined parameter was identified based on a set of distinct expert statements. The grouping of these statements into labels allowed a frequency of nomination analysis, sorting the labels by number of mentions per stakeholder. Additionally, a content analysis aided to locate in which context the statements were made and served to classify the parameters into (S) success factors, (I) suggestions for improvement and (D) deficits. The literature review served to confirm our research findings and to expand the design guideline with additional parameters. The developed design guideline for IIBD in Industry 4.0 serves as an agile document and auxiliary tool, which is easily expandable and can always be enriched with future knowledge enhancement.

The research results provided evidence for the formulated hypotheses that the realization of sustainable industrial buildings is enabled by flexible supporting structures to accommodate fast-moving processes in Industry 4.0. An integrated design approach supported by powerful computational tools is required as industrial building design involves complex interdependencies between interdisciplinary parameters. The presented research identifies the lack of a standardized IIBD approach to realize flexible industrial buildings respecting Industry 4.0 needs already at early design stage, to move the industry towards increased sustainability. The study captures the complex industrial building design process and provides in addition to theoretical support a reference point for future research or developments. With the provided understanding, building owners, designers and engineers can begin to identify underlying design choices and approaches that enable integration and better understand the needs of industrial buildings incorporating Industry 4.0 processes. The developed design guidance provides a basis of transparency for decision-makers to not only follow their own design decision rules. The essence of the proposed parameter catalogue is indeed to go beyond defining one solution. The results of the study underline the need for multi-objective optimization models in IIBD since no single metric or objective can adequately describe the holistic distribution of industrial building design performances. The design guideline can serve as principle requirement framework to build such digital systems and highlights common objectives and parameters in IIBD. However, a limitation of the study is that the formal design guidance does not concentrate on the parameter dependencies and the mathematical formulation of objectives. Future research 
should evaluate the direction and degree of interactions among the parameters to enable variables causal relationship analysis including the level of interactive influence among them. Furthermore, in the presented study, the experts interviewed were involved in industrial building projects from the cleanroom chip, metal processing and food production sectors. To refine the design guideline and gain deeper insights into impacts of different production types on building designs, more production sectors such as paper production, glass production and chemical processes should be investigated and evaluated. Another limitation is that energy planners were not included in this survey, which will be addressed in future research to extend the design guideline.

By identifying the underlying parameters, the categorized design guideline provides a means to describe coherent flexible industrial buildings for Industry 4.0. With the categories presented in this study, the building design and manufacturing industries can begin to standardize their processes and implement flexibility early in the design process. Hence, the study promotes awareness of the importance of flexibility to achieve sustainability and will support design decisions of building owners and planners towards extended industrial building life cycles. In conclusion, this research can be seen as an important milestone towards both integration of building design and production planning as well as a more holistic assessment of sustainability. The obtained results are considered of great practical significance, as building owners, production firms, architects and engineers can efficiently visualize the complex aspects surrounding industrial building design processes in Industry 4.0 environments.

The presented results set the goal for our future research, in which we aim to develop an integrated design approach and a multi-objective optimization and decision support model for automated design and visualization in virtual reality for flexible industrial buildings. Thus, we aim to place the load-bearing structure in the center of the optimization in order to improve the buildings flexibility. Follow-up studies to implement the parameters in a multi-objective optimization and decision support model will also contribute to further validate the proposed data.

Author Contributions: Conceptualization, J.R.; methodology, J.R.; validation, J.R.; formal analysis, P.H.; investigation, P.H.; resources, J.R. and P.H.; data curation, P.H.; writing-original draft preparation, J.R.; writing—review and editing, J.R. and I.K.; visualization, J.R.; supervision, I.K.; project administration, J.R.; funding acquisition, I.K. and J.R. All authors have read and agreed to the published version of the manuscript.

Funding: This research is conducted within the research project "BIMFlexi", which is funded by the Austrian Research Promotion Agency FFG (Österreichische Forschungsförderungsgesellschaft), grant number 877159 . Open Access Funding by TU Wien.

Institutional Review Board Statement: At the time of conducting the study there was no institutional review board for the authors to approach for formal research ethics approval. All interview partners were fully informed about the aims of the research, the use of the collected data, how it would be processed, and of the fact that their anonymity would be ensured.

Informed Consent Statement: Informed consent was obtained from all subjects involved in the study. Moreover, the study participants gave their informed consent for publishing this paper.

Data Availability Statement: The data presented in this study are available on request from the corresponding author.

Acknowledgments: The authors would particularly like to thank the experts from industry who agreed to be interviewed and the austrian funding agency FFG for the research funding.

Conflicts of Interest: The authors declare no conflict of interest. The funders had no role in the design of the study; in the collection, analyses, or interpretation of data; in the writing of the manuscript, or in the decision to publish the results. 


\section{References}

1. Oesterreich, T.D.; Teuteberg, F. Understanding the implications of digitisation and automation in the context of Industry 4.0: A triangulation approach and elements of a research agenda for the construction industry. Comput. Ind. 2016, 83, 121-139. [CrossRef]

2. Xu, L.D.; Xu, E.L.; Li, L. Industry 4.0: State of the art and future trends. Int. J. Prod. Res. 2018, 56, 2941-2962. [CrossRef]

3. Lasi, H.; Fettke, P.; Kemper, H.-G.; Feld, T.; Hoffmann, M. Industry 4.0. Bus. Inf. Syst. Eng. 2014, 6, 239-242. [CrossRef]

4. Dallasega, P.; Rauch, E.; Linder, C. Industry 4.0 as an enabler of proximity for construction supply chains: A systematic literature review. Comput. Ind. 2018, 99, 205-225. [CrossRef]

5. Oláh, J.; Aburumman, N.; Popp, J.; Khan, M.; Haddad, H.; Kitukutha, N. Impact of Industry 4.0 on environmental sustainability. Sustainability 2020, 12, 4674. [CrossRef]

6. Climate Change: Status, Challenges, and Opportunities; United Nations Environment Programme, Sustainable Buildings and Construction Initiative: Paris, France, 2007.

7. Röck, M.; Hollberg, A.; Habert, G.; Passer, A. LCA and BIM: Visualization of environmental potentials in building construction at early design stages. Build. Environ. 2018, 140, 153-161. [CrossRef]

8. Heravi, G.; Fathi, M.; Faeghi, S. Evaluation of sustainability indicators of industrial buildings focused on petrochemical projects. J. Clean. Prod. 2015, 109, 92-107. [CrossRef]

9. A/RES/70/1 Transforming Our World: The 2030 Agenda for Sustainable Development; United Nations: New York, NY, USA, 2015.

10. Ejsmont, K.; Gladysz, B.; Kluczek, A. Impact of Industry 4.0 on Sustainability-Bibliometric Literature Review. Sustainability 2020, 12, 5650. [CrossRef]

11. Zanni, M.; Soetanto, R.; Ruikar, K. Towards a BIM-enabled sustainable building design process: Roles, responsibilities, and requirements. Archit. Eng. Des. Manag. 2016, 13, 101-129. [CrossRef]

12. Boujaoude Khoury, K. Effective communication processes for building design, construction, and management. Buildings 2019, 9, 112. [CrossRef]

13. Kin, M.; Dawood, N.; Kassem, M. BIM for manufacturing: A case study demonstrating benefits and workflows and an approach for Enterprise Application Integration (EAI). In Proceedings of the 13th International Conference on Construction Applications of Virtual Reality, Hong Kong, 12-13 December 2016.

14. Näser, P.; Wickenhagen, N. Factory integration into building information modeling (BIM). In wt Werkstattstechnik Online Jahrgang 108 (2018); Springer-VDI-Verlag GmbH \& Co. KG: Düsseldorf, Germany, 2018; pp. 245-250.

15. Peukert, B.; Benecke, S.; Clavell, J.; Neugebauer, S.; Nissen, N.F.; Uhlmann, E.; Lang, K.-D.; Finkbeiner, M. Addressing sustainability and flexibility in manufacturing via smart modular machine tool frames to support sustainable value creation. Procedia CIRP 2015, 29, 514-519. [CrossRef]

16. Gosling, J.; Naim, M.; Sassi, P.; Iosif, L.; Lark, R. Flexible buildings for an adaptable and sustainable future. In Proceedings of the Association of Researchers in Construction Management (ARCOM) 24th Annual Conference, Cardiff, UK, 1-3 September 2008.

17. Cavalliere, C.; Dell'Osso, G.R.; Favia, F.; Lovicario, M. BIM-based assessment metrics for the functional flexibility of building designs. Autom. Constr. 2019, 107, 102925. [CrossRef]

18. Gourlis, G.; Kovacic, I. Building Information Modelling for analysis of energy efficient industrial buildings-A case study. Renew. Sustain. Energy Rev. 2017, 68, 953-963. [CrossRef]

19. Madson, K.M.; Franz, B.; Molenaar, K.R. Okudan Kremer Strategic development of flexible manufacturing facilities. Eng. Constr. Archit. Manag. 2020, 27, 1299-1314. [CrossRef]

20. Sahinidis, N.V.; Grossmann, I.E. Multiperiod investment model for processing networks with dedicated and flexible plants. Ind. Eng. Chem. Res. 1991, 30, 1165-1171. [CrossRef]

21. Flager, F. The Design of Building Structures for Improved Life-Cycle Performance. Master's Thesis, Massachusetts Institute of Technology, Cambridge, MA, USA, 2003.

22. Graubner, C. Der Stadtbaustein im DAfStb/BMBF-Verbundforschungsvorhaben "Nachhaltig Bauen mit Beton"; Deutscher Ausschuss für Stahlbeton e.V.-DafStb, Beuth: Berlin, Germany, 2014.

23. Slaughter, E.S. Design strategies to increase building flexibility. Build. Res. Inf. 2001, 29, 208-217. [CrossRef]

24. Rolvink, A.; Breider, J.; Coenders, J. Structural Components-A parametric associative design toolbox for conceptual structural design. In Proceedings of the International Association for Shell and Spatial Structures (IASS) Symposium. Evolution and Trends in Design, Analysis and Construction of Shell and Spatial Structures, Valencia, Spain, 28 September-2 October 2009; Universidad Politecnica de Valencia: Valencia, Spain, 2009.

25. Mueller, C.T.; Ochsendorf, J.A. Combining structural performance and designer preferences in evolutionary design space exploration. Autom. Constr. 2015, 52, 70-82. [CrossRef]

26. Di Giuda, G.M.; Giana, P.E.; Schievano, M.; Paleari, F. A collaborative approach for AEC industry digital transformation: A case study, the School of Liscate. In Buildings for Education: A Multidisciplinary Overview of the Design of School Buildings; Della Torre, S., Bocciarelli, M., Daglio, L., Neri, R., Eds.; Springer International Publishing: Cham, Germany, 2020; pp. 175-184. [CrossRef]

27. Ebade Esfahani, M.; Burggräf, P.; Dannapfel, M.; Schneidermann, D.; Schwamborn, N. Integrated factory modelling: Using BIM to disrupt the interface between manufacturing and construction in factory planning. WIT Trans. Built Environ. 2019, 192, 143-155. [CrossRef] 
28. Büscher, C.; Meisen, T.; Schilberg, D.; Jeschke, S. VPI-FP: An integrative information system for factory planning. Int. J. Prod. Res. 2016, 54, 2215-2226. [CrossRef]

29. Francalanza, E.; Borg, J.; Constantinescu, C. Development and evaluation of a knowledge-based decision-making approach for designing changeable manufacturing systems. CIRP J. Manuf. Sci. Technol. 2017, 16, 81-101. [CrossRef]

30. Mousavi, S.; Thiede, S.; Li, W.; Kara, S.; Herrmann, C. An integrated approach for improving energy efficiency of manufacturing process chains. Int. J. Sustain. Eng. 2016, 9, 11-24. [CrossRef]

31. Garwood, T.L.; Hughes, B.R.; Oates, M.R.; O'Connor, D.; Hughes, R. A review of energy simulation tools for the manufacturing sector. Renew. Sustain. Energy Rev. 2018, 81, 895-911. [CrossRef]

32. Deif, A.M. A system model for green manufacturing. J. Clean. Prod. 2011, 19, 1553-1559. [CrossRef]

33. Kluczek, A. An overall multi-criteria approach to sustainability assessment of manufacturing processes. Procedia Manuf. 2017, 8 , 136-143. [CrossRef]

34. Kovacic, I.; Waltenbereger, L.; Gourlis, G. Tool for life cycle analysis of facade-systems for industrial buildings. J. Clean. Prod. 2016, 130, 260-272. [CrossRef]

35. Rodrigues, V.; Martins, A.A.; Nunes, M.I.; Quintas, A.; Mata, T.M.; Caetano, N.S. LCA of constructing an industrial building: Focus on embodied carbon and energy. Energy Procedia 2018, 153, 420-425. [CrossRef]

36. Tulevech, S.M.; Hage, D.J.; Jorgensen, S.K.; Guensler, C.L.; Himmler, R.; Gheewala, S.H. Life cycle assessment: A multi-scenario case study of a low-energy industrial building in Thailand. Energy Build. 2018, 168, 191-200. [CrossRef]

37. Bleicher, F.; Duer, F.; Leobner, I.; Kovacic, I.; Heinzl, B.; Kastner, W. Co-simulation environment for optimizing energy efficiency in production systems. CIRP Ann. 2014, 63, 441-444. [CrossRef]

38. Gourlis, G.; Kovacic, I. A study on building performance analysis for energy retrofit of existing industrial facilities. Appl. Energy 2016, 184, 1389-1399. [CrossRef]

39. Chen, D.; Heyer, S.; Seliger, G.; Kjellberg, T. Integrating sustainability within the factory planning process. CIRP Ann. 2012, 61, 463-466. [CrossRef]

40. Zhao, T.; Tseng, C.-L. Valuing flexibility in infrastructure expansion. J. Infrastruct. Syst. 2003, 9, 89-97. [CrossRef]

41. Geraedts, R. FLEX 4.0, a practical instrument to assess the adaptive capacity of buildings. Energy Procedia 2016, 96, 568-579. [CrossRef]

42. Cardin, M.-A.; Ranjbar-Bourani, M.; de Neufville, R. Improving the lifecycle performance of engineering projects with flexible strategies: Example of on-shore LNG production design. Syst. Eng. 2015, 18, 253-268. [CrossRef]

43. Marjaba, G.; Chidiac, S.E. Sustainability and resiliency metrics for buildings-Critical review. Build. Environ. 2016, 101, 116-125. [CrossRef]

44. Upton, D. What really makes factories flexible. Harv. Bus. Rev. 1995, 73, 74-85.

45. De Paris, S.R.; Lopes, C.N.L. Housing flexibility problem: Review of recent limitations and solutions. Front. Archit. Res. 2018, 7, 80-91. [CrossRef]

46. Cellucci, C.; Sivo, M. The flexible housing: Criteria and strategies for implementation of the flexibility. J. Civ. Eng. Archit. 2015, 9, 845-852. [CrossRef]

47. Živković, M.; Jovanović, G. A method for evaluating the degree of housing unit flexibility in multi-family housing. Archit. Civ. Eng. 2012, 10, 17-32. [CrossRef]

48. Glumac, B.; Islam, N. Housing preferences for adaptive re-use of office and industrial buildings: Demand side. Sustain. Cities Soc. 2020, 62, 102379. [CrossRef]

49. Israelsson, N. Factors influencing flexibility in buildings. Struct. Surv. 2009, 27, 138-147. [CrossRef]

50. Browne, J.; Dubois, D.; Rathmill, K.; Sethi, S.; Stecke, K. Classification of flexible manufacturing systems. FMS Mag. 1984, 2, 114-117.

51. Sethi, A.K.; Sethi, S.P. Flexibility in manufacturing: A survey. Int. J. Flex. Manuf. Syst. 1990, 2, 289-328. [CrossRef]

52. Wiendahl, H.P.; El Maraghy, H.A.; Nyhuis, P.; Zäh, M.F.; Wiendahl, H.H.; Duffie, N.; Brieke, M. Changeable manufacturingClassification, design and operation. CIRP Ann. 2007, 56, 783-809. [CrossRef]

53. Moline, A. Recipe for Change: The Flexible Food Processing Plant of the Future. In DesignFlex2030, Industrial Asset Management Council (IAMC) and SIOR, GA, USA. 2015. Available online: https:/ /www.sior.com/docs/default-source/default-documentlibrary / DesignFlex2030.pdf (accessed on 17 September 2021).

54. Moline, A. Rx for change: The Flexible Biopharma Facility of the Future, In DesignFlex2030, Industrial Asset Management Council (IAMC) and SIOR, GA, USA. 2017. Available online: https://www.sior.com/docs/default-source/white-papers/dflex2 030---rx-for-change.pdf?sfvrsn=0 (accessed on 17 September 2021).

55. Cardin, M.-A. Enabling flexibility in engineering systems: A taxonomy of procedures and a design framework. J. Mech. Des. 2014, 136, 011005. [CrossRef]

56. Shen, L.; Tam, V.; Yao, H. A checklist for assessing sustainability performance of construction projects. J. Civ. Eng. Manag. 2007, 13, 273-281. [CrossRef]

57. Shen, L.; Asce, M.; Wu, Y.; Zhang, X. Key assessment indicators for the sustainability of infrastructure projects. J. Constr. Eng. Manag. 2011, 137, 441-451. [CrossRef]

58. San-José Lombera, J.-T.; Garrucho Aprea, I. A system approach to the environmental analysis of industrial buildings. Build. Environ. 2010, 45, 673-683. [CrossRef] 
59. Heravi, G.; Fathi, M.; Faeghi, S. Multi-criteria group decision-making method for optimal selection of sustainable industrial building options focused on petrochemical projects. J. Clean. Prod. 2017, 142, 2999-3013. [CrossRef]

60. Nadoushani, Z.; Akbarnezhad, A. Effects of structural system on the life cycle carbon footprint of buildings. Energy Build. 2015, 102, 337-346. [CrossRef]

61. Lee, B.; Pourmousavian, N.; Hensen, J.L.M. Full-factorial design space exploration approach for multi-criteria decision making of the design of industrial halls. Energy Build. 2016, 117, 352-361. [CrossRef]

62. Vardopoulos, I. Critical sustainable development factors in the adaptive reuse of urban industrial buildings. A fuzzy DEMATEL approach. Sustain. Cities Soc. 2019, 50, 101684. [CrossRef]

63. Wiendahl, P.; Reichardt, J.; Nyhuis, P. Handbook Factory Planning and Design; Springer: Berlin/Heidelberg, Germany, 2015; Volume 1. [CrossRef]

64. Woodhead, R.; Stephenson, P.; Morrey, D. Digital construction: From point solutions to IoT ecosystem. Autom. Constr. 2018, 93, 35-46. [CrossRef]

65. Grilo, A.; Jardim-Goncalves, R. Value proposition on interoperability of BIM and collaborative working environments. Autom. Constr. 2010, 19, 522-530. [CrossRef]

66. Sibenik, G.; Kovacic, I. Assessment of model-based data exchange between architectural design and structural analysis. J. Build. Eng. 2020, 32, 101589. [CrossRef]

67. Succar, B. Building information modelling framework: A research and delivery foundation for industry stakeholders. Autom. Constr. 2009, 18, 357-375. [CrossRef]

68. Zhang, X.; Azhar, S.; Nadeem, A.; Khalfan, M. Using building information modelling to achieve lean principles by improving efficiency of work teams. Int. J. Constr. Manag. 2018, 18, 300. [CrossRef]

69. Rahmani Asl, M.; Zarrinmehr, S.; Bergin, M.; Yan, W. BPOpt: A framework for BIM-based performance optimization. Energy Build. 2015, 108, 401-412. [CrossRef]

70. Schuh, G.; Kampker, A.; Wesch-Potente, C. Condition based factory planning. Prod. Eng. 2011, 5, 89-94. [CrossRef]

71. Bejjani, C.; Utsch, J.; Thiele, T.; Meisen, T.; Jeschke, J.; Burggräf, P. Flow Chart based information modeling for factory planning. Procedia CIRP 2018, 72, 410-415. [CrossRef]

72. Hawer, S.; Sager, B.; Braun, H.; Reinhart, G. An adaptable model for the factory planning process: Analyzing data based interdependencies. Procedia CIRP 2017, 62, 117-122. [CrossRef]

73. Kampker, A.; Mecklenborg, A.; Burggräf, P.; Netz, T. Factory planning scrum: Integrative factory planning with agile project management. In Proceedings of the International Conference on Competitive Manufacturing (COMA '13), Stellenbosch, South Africa, 30 January-1 February 2013.

74. Graefenstein, J.; Winkels, J.; Lenz, L.; Weist, K.C.; Krebil, K.; Gralla, M. A hybrid approach of modular planning—Synchronizing factory and building planning by using component based synthesis. In Proceedings of the 53rd Hawaii International Conference on System Sciences, Wailea, HI, USA, 7-10 January 2020.

75. Lenz, L.T.; Gralla, M.; Höpfner, M.; Spyridis, P.; Weist, K.C. BIM approach for decision support: Case study fastening systems in factory adaptation planning. In Proceedings of the 2019 European Conference on Computing in Construction, Chania, Greece, 10-12 July 2019; pp. 2-8. [CrossRef]

76. Delbrügger, T.; Lenz, L.T.; Losch, D.; Roßmann, J. A navigation framework for digital twins of factories based on building information modeling. In Proceedings of the 22nd IEEE International Conference on Emerging Technologies and Factory Automation (ETFA), Limassol, Cyprus, 12-15 September 2017. [CrossRef]

77. The design process-Early stages. In The ASHRAE GreenGuide, 2nd ed.; Butterworth-Heinemann: Burlington, MA, USA, 2006; pp. 73-100.

78. Sadafi, N.; Mohd Zain, M.F.; Jamil, M. Design criteria for increasing building flexibility: Dynamics and prospects. Environ. Eng. Manag. J. 2014, 13, 407-417. [CrossRef]

79. Lee, J.H.; Ostwald, M.J. Creative decision-making processes in parametric design. Buildings 2020, 10, 242. [CrossRef]

80. Büscher, C.; Voet, H.; Meisen, T.; Krunke, M.; Kreisköther, K.; Kampker, A.; Schilberg, D.; Jeschke, S. Improving factory planning by analyzing process dependencies. Procedia CIRP 2014, 17, 38-43. [CrossRef]

81. Cuadrado, J.; Zubizarreta, M.; Roji, M.; García, H.; Larrauri, M. Sustainability-related decision making in industrial buildings: An AHP analysis. Math. Probl. Eng. 2015, 2015, 157129. [CrossRef]

82. Chinese, D.; Nardin, G.; Saro, O. Multi-criteria analysis for the selection of space heating systems in an industrial building. Energy 2011, 36, 556-565. [CrossRef]

83. Albers, S.; Klapper, D.; Konradt, U.; Walter, A.; Wolf, J. Methodik der Empirischen Forschung; Gabler Verlag: Wiesbaden, Germany, 2009. [CrossRef]

84. Bogner, A.; Littig, B.; Menz, W. Interviews mit Experten. Eine Praxisorientierte Einführung; Springer: Berlin/Heidelberg, Germany, 2014; Volume 1. [CrossRef]

85. Radson, D.; Boyd, A.H. The pareto principle and rate analysis. Qual. Eng. 1997, 10, 223-229. [CrossRef]

86. Kovacic, I.; Müller, C. Challenges for the implementation of integrated design in the planning practice. Procedia-Soc. Behav. Sci. 2014, 119, 529-538. [CrossRef] 